\title{
Sexual reproduction in Populus II. Information molecules of the pollen grain
}

\author{
M. Gaget ${ }^{1}$, M. Villar ${ }^{2}$, C. Kerhoas ${ }^{1}$ and C. Dumas ${ }^{1}$
}

'Laboratoire de Reconnaissance Cellulaire et Amelioration des Plantes INRA 23879, Université Lyon I, 43, bd 11-novembre-1918, F-69622 Villeurbanne Cedex, and

2INRA, Station d'Amélioration des Arbres Forestiers, Ardon, F-45160 Olivet, France

\section{Introduction}

Sexual interactions in flowering plants depend upon pollen-pistil biocommunications, involving biochemical signals exchanged between the mating partners. Such components involved in self-incompatibility are known to be the primary products of the $S$ (self-incompatibility) gene. They are of protein and glycoprotein nature (Nasrallah and Nasrallah, 1986; Gaude and Dumas, 1987). On the other hand, no data are available on the pollinic signals implicated in interspecific incompatibility of self-compatible species.

Cellular localization and biochemical identification of pollinic molecules, likely to be implicated in interspecific incompatibility in Poplars, are presented in this paper. Our model involves 2 species of section Aigeiros (Populus nigra, $P$. deltoides) and one species of section Leuce ( $P$. alba). Crosses between species of these 2 botanical sections are strictly incompatible.

\section{Materials and Methods}

$P$. nigra, $P$. deltoides and $P$. alba branches were obtained from the INRA Forestry Station in Orléans (France). Pollen was collected and stored in closed vials at $-18^{\circ} \mathrm{C}$.

For cytochemistry, ultrathin pollen sections were prepared according to Gaget (1988). They were stained with uranyl acetate/lead citrate (Reynolds, 1963), and observed at $80 \mathrm{kV}$ with the Hitachi HU 12A microscope at CMEABG, University of Lyon, France.

Freeze-fracture was performed according to Kerhoas et al. (1987) and replicas were observed by transmission electron microscopy (TEM).

Pollen prints were obtained by placing pollen grains onto a formvar-coated grid for $30 \mathrm{~min}$ in humid Petri dishes. Grids were then stained (uranyl acetate/lead citrate; Reynolds, 1963) and observed by TEM.

Biochemical analysis: pollen diffusates were obtained by putting pollen grains in Tris buffer $(\mathrm{pH} 7.5,25 \mathrm{mM})$ for $10 \mathrm{~min}$ at $4^{\circ} \mathrm{C}$. After centrifugation, the supernatant was filtered and concentrated by acetone precipitation. The resuspended extracts were assayed for total proteins, according to Bradford (1976), with bovine serum albumin as a standard. Samples 

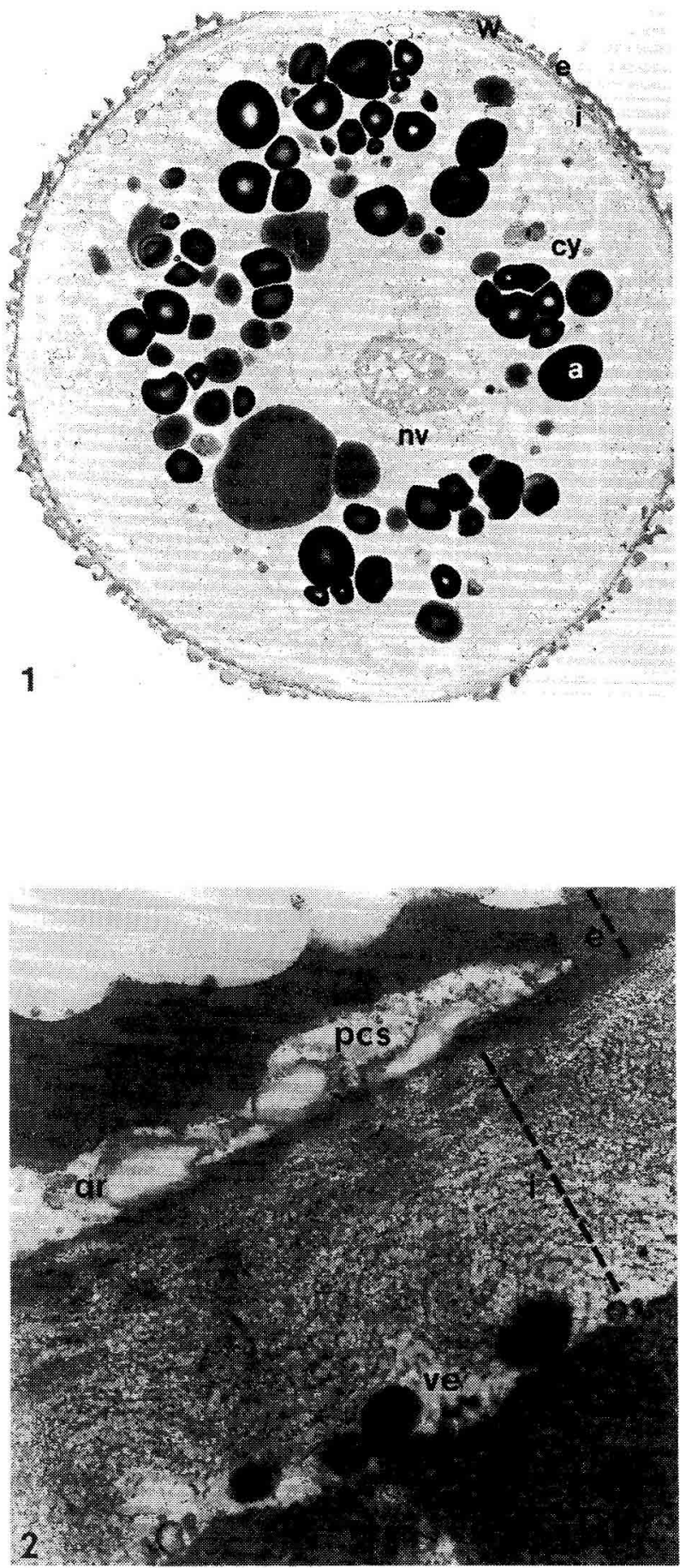

Fig. 1. TEM observation of the polIen grain of $P$. alba. At maturity, the bicellular pollen grain contains a vegetative nucleus (nv) and a gererative nucleus (not visible here). The generative cell lies within the cytoplasm (cy) of the vegetative cell. The pollen grain is surrounded by a complex wall (w), with 2 distinct layers, intine (i) and exine (e). Numerous amyloplasts (a) are observed in the cytoplasm of the pollen glrain ( $\times 5000$, PATAg test).

Fig. 2. Pollen wall structure of $P$. alba. Exine (e): the arcades of the exine (ar) contain pollen coat substances (pcs), likely to be involved in pollen-pistil interactions. Intine (i): osmiophilic vesicles (ve) are observed within the intine. (TEM, $x$ 48000 , uranyl acetate/lead citrate stain). 


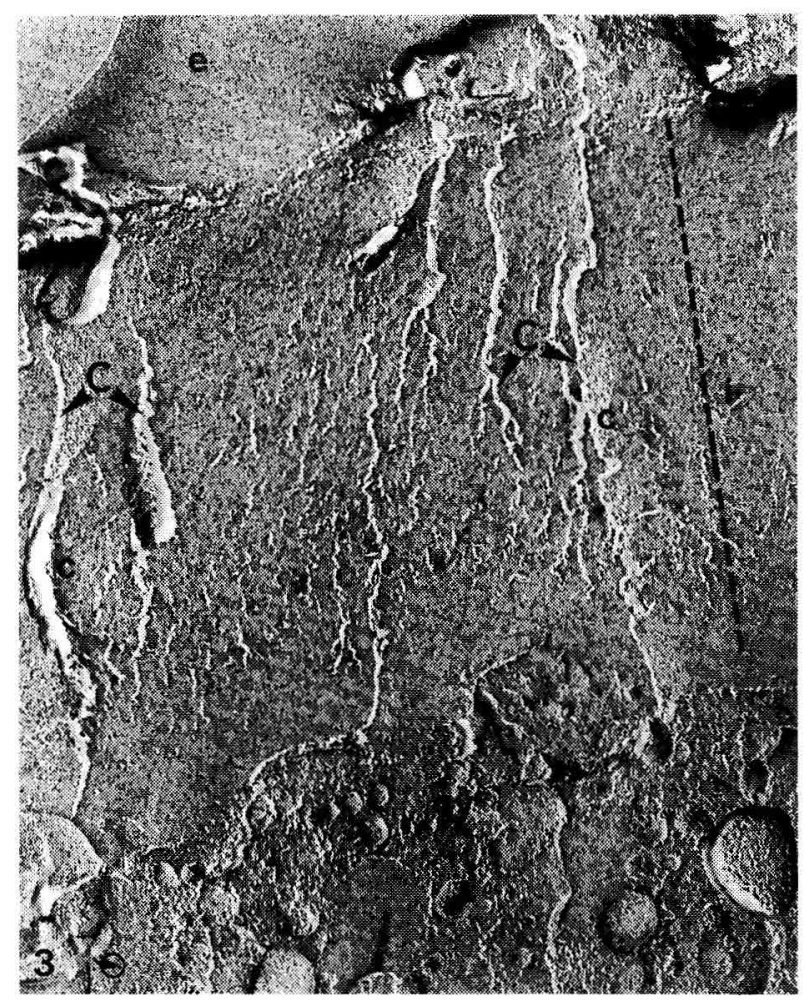

Fig. 3. Freeze-fracture replica of $P$. alba pollen. This replica shows the presence of microchannels (c) through the intine (i) allowing recognition material to diffuse from the cytoplasm (cy) of the pollen grain. (TEM, $x 48000$ ).

containing 10 us of protein were loaded on an. SDS-gel, according to Laemmli's procedure (Laemmli, 1970). After running, proteins were stained with silver nitrate (Morrissey, 1981). Proteins were electrophoretically transferred onto a nitrocellulose sheet (Towbin et al., 1979) and the glycoproteins revealed by the Con A-peroxidase method (Hawkes, 1982).

\section{Results and Discussion}

Ultrastructural observations (TEM) show a bicellular pollen grain containing a vegetative nucleus, a generative nucleus, the cytoplasm of the vegetative cell with numerous amyloplasts and a bilayered pollen wall with a thin semi-tected exine (Figs. 1 and 2). The presence of a great amount of osmiophilic components in the pollen coat is observed within the arcades of the exine (Fig. 2). These components were also reactive in the polysaccharide and glycoconjugate detection test (Gaget, 1988). These components are able to diffuse rapidly from the pollen grain, as shown by pollen prints (not illustrated). Such diffusible materials are of polysaccharidic nature and contain glycoconjugates (Gaget, 1988). The freeze-fracture replicas show the presence of microchannels through the fibrillar intine (Fig. 3). These structures might be the pathway of diffusible pollinic components from the vegetative cell to the external surface. Such microchannels have been observed in the papillar wall of the female partner 


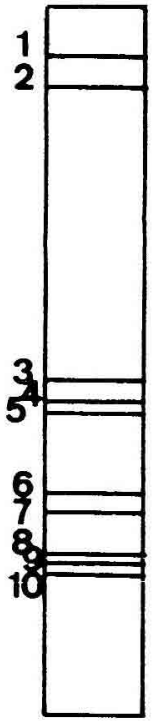

A

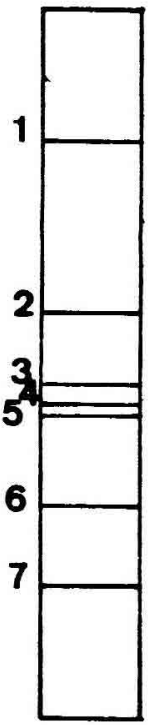

N

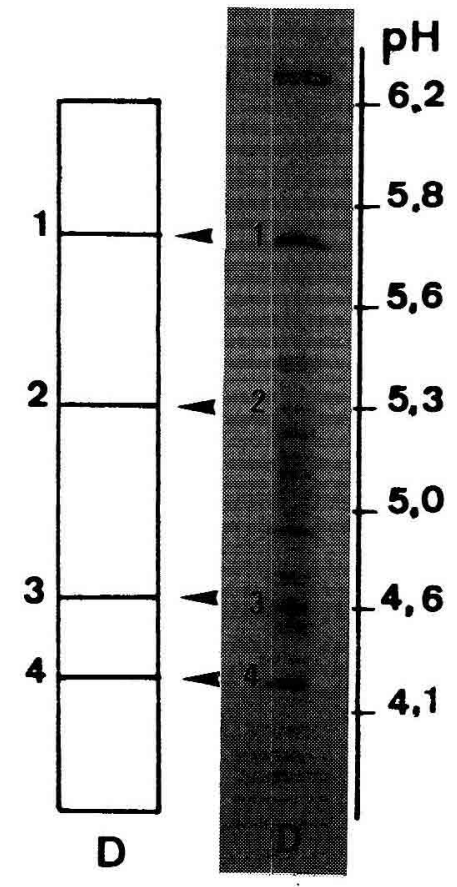

Fig. 4. Diffusable pollinic glycoproteins (Con A-binding proteins). Arrowheads: similar glycoprotein bands of species of section Aigeiros ( $P$. nigra and $P$. deltoides). N: $P$. nigra; D: $P$. deltoides; A: $P$. alba.

and were implicated in the transport of recognition proteins to the female surface (Clarke et al., 1980).

Globular proteins with molecular mass of 100000 Da may be able to diffuse across the pollen wall by means of canaliculi whose diameter was estimated to be $30 \mathrm{~nm}$. Protein assay showed that, depending upon the species used, $5-20 \%$ of the pollinic proteins diffuse in $10 \mathrm{~min}$ in Tris buffer, without affecting pollen viability. This protein fraction contains numerous protein bands whose molecular masses ranged between 10000 and $100000 \mathrm{Da}$. Among them, we found some peculiar bands associated with the group of incompatibility (Fig. 4). Some are specific to Aigeiros species (present in $P$. nigra and $P$. deltoides). Others are specific to Leuce species (present in $P$. alba). Moreover, these bands were also revealed by the Con A-peroxiclase procedure and could be considered as glycoproteins.

\section{Conclusion}

Our work clearly demonstrates the existence of specific glycoproteins, whose presence in pollen is related to sexual incompatibility. Such a study should be extended to other species of the 5 sections of the genus Populus. Moreover, extraction and use of these specific glycoproteins implicated in pollen-pistil recognition could be an attractive tool for overcoming interspecific incompatibility in poplars. 


\section{References}

Bradford M.M. (1976) A rapid and sensitive method for the quantitation of microgram quantities of protein utilizing the principle of protein dye binding. Anal. Biochem. 72, 249-254

Clarke A.E., Abbot A., Mandel T.E. \& Pettitt J.M. (1980) Organisation of the wall layers of the stigmatic papillae of Gladiolus gandavensis: a freeze fracture study. J. Ultrastruct. Res. 73, 269-281

Gaget M. (1988) Incompatibilité interspécifique chez Populus: effet Mentor. Ph.D. Thesis, Université Lyon I, France

Gaude T. \& Dumas C. (1987) Molecular and cellular events of self-incompatibility. Int. Rev. Cytol. 107, 333-366

Hawkes R. (1982) Identification of Con A binding proteins after SDS gel electrophoresis and protein blotting. Anal. Biochem. 123, 143-146
Kerhoas C., Gay G. \& Dumas C. (1987) A multidisciplinary approach to the study of the plasma membrane of Zea mays pollen during controlled dehydration. Planta 171, 1-10

Laemmli U.K. (1970) Cleavage of structural proteins during the assembly of the head of bacteriophage T4. Nature 227, 680-685

Morrissey J.H. (1981) Silver stain for proteins in polyacrylamide gels: a modified procedure with enhanced uniform sensitivity. Anal. Biochem. 117, 307-310

Nasrallah M.E. \& Nasrallah J.B. (1986) Molecular Biology of self incompatibility in plants. Trends Genet. 2, 239-244

Reynolds E.S. (1963) The use of lead citrate at high $\mathrm{pH}$ as an electron opaque stain electron microscopy. J. Cell Biol. 17, 208-212

Towbin H., Staehelin T. \& Gordon J. (1979) Electrophoretic transfer of proteins from polyacrylamide gels to nitrocellulose sheets: procedure and some applications. Proc. Natl. Acad. Sci. USA 76, 4350-4354 